\section{Constituintes químicos de Burlemarxia rodriguesii Menezes \& Semir (Velloziaceae)}

\section{Adriana Brügger Alves*; Valdir Florêncio da Veiga Júnior; Angelo da Cunha Pinto}

Instituto de Química, Departamento de Química Orgânica, UFRJ, Cidade Universitária, 21945-920, Rio de Janeiro, RJ, Brasil

brugger@iq.ufrj.br

\section{Resumo}

Neste trabalho foi analisado o extrato apolar de Burlemarxia rodriguesii Menezes \& Semir através da análise direta do extrato por métodos cromatográficos. $\mathrm{Na}$ análise por Cromatografia Gasosa de Alta Resolução (CGAR) e da Cromatografia de Alta Resolução acoplada à Espectrometria de Massas (CGAR-EM) foram detectados apenas os compostos majoritários. Para determinar os demais constituintes químicos presentes neste extrato foi realizado um pré-fracionamento no qual classes químicas como ácidos graxos, ésteres graxos, esteróis e terpenóides foram separados. A metodologia empregada permitiu a detecção e identificação de várias substâncias e séries homólogas através de co-injeções com padrões (em CGAR) e comparação de espectros (CGAR-EM).

A família Velloziaceae apresenta cerca de 270 espécies divididas entre seis gêneros: Vellozia, Barbacenia, Xerophyta, Pleurostima, Aylthonia e Burlemarxia (sensu Menezes \& Semir) ${ }^{1,2}$. Estes dois últimos gêneros são novos e ainda sem nenhum estudo fitoquímico. Esta família se distribui no Brasil, principalmente na Serra do Cipó e em algumas regiões da África. No estudo da família Velloziaceae existem várias controvérsias com relação à posição cladística de seus gêneros e espécies ${ }^{1,3}$. Uma das formas de auxiliar na solução deste problema é a des- crição fitoquímica das espécies.

A investigação da composição química das espécies desta família vem sendo realizada ao longo de vários anos em nosso grupo, com o isolamento de cerca de 250 terpenóides, entre di e triterpenos. A confecção deste banco de padrões possibilita a análise direta de extratos por métodos cromatográficos ${ }^{4}$, uma das formas mais utilizadas de identificação de substâncias em extratos apolares de plantas, medicinais ou não.

Esta análise, entretanto, terá seus resultados comprometidos se o extrato apresentar grande diversidade de compostos orgânicos ou grande quantidade de moléculas graxas, como hidrocarbonetos, ácidos graxos e derivados de degradação de clorofila, como o fitol.

Nesta comunicação, descreve-se o estudo através da CGAR-EM do extrato de baixa polaridade de Burlemarxia rodriguesii Menezes \& Semir².

$\mathrm{O}$ extrato em hexano de Burlemarxia rodriguesii, esterificado com diazometano, foi analisado por CGAR. Obtido o perfil cromatográfico, o extrato foi submetido à análise por CGAR-EM. A análise do cromatograma de íons totais (CIT) do extrato de baixa polaridade só permitiu a detecção dos compostos majoritários. Foram detectados os ácidos palmítico, oléico, linoléico e esteárico (detectados na forma de ésteres metílicos), éster etílico do ácido palmítico, lupenona, estigmast-4-en-3-ona e tritriacontano.

De modo a possibilitar a análise de compostos minoritários foi realizado um fracionamento em coluna aberta recheada com gel de sílica utilizando quatro eluentes diferentes (heptano, heptano:éter etílico 8:2, éter etílico: acetato de etila 8:2), resultando num total de 5 frações. As frações mais polares foram esterificadas com diazometano para análise em CGAR e CGAR-EM, uma vez que foi utilizada coluna capilar contendo uma fase estacionária de baixa polaridade.

Para a confirmação das substâncias detectadas foi necessário buscar alguns padrões para co-injeção em CGAR. Os padrões de ésteres metílicos e etílicos e esteróis ${ }^{5}$ foram obtidos a partir de extrações e transformações em óleos de soja e de oliva. Os diterpenos e triterpenos foram selecionados no

Tabela 1. Composição das frações do extrato em hexano de Burlemarxia rodriguesii

\begin{tabular}{l|ll}
\hline Código das frações & Compostos identificados & Forma de identificação \\
\hline BRH1 & Série homóloga de hidrocarbonetos (C17-C35) & IR e FM \\
\hline BRH2 & Série de ésteres etílicos (C16-C28) & IR, FM e CO \\
\hline \multirow{3}{*}{ BRH3 } & lupenona, $\beta$-amirona & CO \\
\cline { 2 - 3 } & $\Delta^{18}$ fridelen-3-ona, alnusenona & IR EM \\
& $\alpha$ e $\beta$ amirinas & IR e EM \\
\cline { 2 - 3 } & $\begin{array}{l}\text { Ácidos diterpênicos: labda-8(17)-13-dien-18-óico, catívico, } \\
\text { halim-1(10)-en-15-óico e clerod-3-en-15-óico }\end{array}$ \\
\cline { 2 - 3 } & Série homóloga de ésteres metílicos (C14-C30) & IR, FM e CO \\
\cline { 2 - 3 } BRH5 & Campesterol, Estigmasterol, $\beta$-sitosterol & IR e EM \\
\cline { 2 - 3 } & Acetatos de $\alpha$ e $\beta$-amirina e $\Delta^{18}$ fridelen-3-ol & IR e EM \\
\hline
\end{tabular}

IR - Identificação realizada através de índices de retenção

EM - Identificação realizada através de comparação visual ou automática dos espectros de massas

FM - Componentes em composição minoritária detectados utilizando-se fragmentografia de massas

CO - Identificação realizada através de co-injeções em CGAR utilizando padrões em duas fases estacionárias diferentes 
banco de padrões do grupo.

A tabela 1 mostra de uma forma simples a composição das frações.

As séries homólogas foram identificadas através de seus tempos de retenção, comparados com padrões, e de seus íons característicos, observados por espectrometria de massas. Foram identificadas séries homólogas de hidrocarbonetos (C17C35), ésteres etílicos de ácidos graxos (C16-C28) e ácidos graxos (C14-C30).

Através de seus espectros de massas foram detectados os triterpenos: acetato de $\Delta 18$-fridelen-3-ol, lupenona, $\alpha$ e $\beta$ amirinas e seus acetatos, $\beta$ amirona, alnusenona e $\Delta 18$-fridelen-3-ona; os ácidos diterpênicos: clerod-3-en-15-óico, labda-8(17)-13-dien18-óico e catívico; e os esteróis: campesterol, estigmasterol, $\beta$ sitosterol e estigmast-4-en-3-ona.

Os triterpenos pentacíclicos $\alpha$ e $\beta$ amirona e lupenona foram detectados através de seus espectros de massas e a identificação confirmada através de co-injeção com padrões.

A identificação de compostos em extratos vegetais geralmente passa pelo fracionamento exaustivo, no processo conhecido como fitoquímica clássica, ou pela identificação direta em extratos brutos, com o uso de padrões. O pré-fracionamento realizado foi uma alternativa intermediária e eficiente para a identificação de compostos em extratos apolares, permitindo a identificação de várias séries homólogas e de misturas de esteróis e terpenóides em pouco tempo e com um gasto mínimo de solventes e adsorventes.

\section{Material e Métodos}

As folhas, raízes, tronco e bainha foliar de Burlemarxia rodriguesii Menezes \& Semir foram coletadas no município de Gouveia, na Serra do Cipó, Chapada Diamantina, MG, em Novembro de 1993. O espécime foi identificado pela Dra. Nanuza L. Menezes, do Instituto de Botânica da Universidade de São Paulo e uma exsicata foi depositada no herbário do mesmo instituto. $\mathrm{O}$ extrato de baixa polaridade foi obtido com todas as partes coletadas, através de percolação com hexano a frio por 15 dias.

As análises cromatográficas foram feitas em cromatógrafo de gás HP 5790 e HP 5880 acoplado à espectrômetro de massas HP 5987A (ionização por impacto de elétrons $-70 \mathrm{eV}$ e analisador quadrupolo). As condições de análise foram as mesmas para os dois instrumentos: gás de arraste: $\mathrm{H}_{2}$, fluxo: $2 \mathrm{ml} / \mathrm{min}$, injetor: $270^{\circ} \mathrm{C}$, detector por ionização de chama: $300^{\circ} \mathrm{C}$, coluna SE- $54, \mathrm{DI}=0,25 \mathrm{~mm}, \mathrm{df}_{\mathrm{f}}=0,25 \mu \mathrm{m}, \mathrm{L}=15 \mathrm{~m}$, programação de temperatura: $100{ }^{\circ} \mathrm{C} \mathrm{a} 290{ }^{\circ} \mathrm{C}, 4^{\circ} \mathrm{C} / \mathrm{mim}$.

\section{Referências}

${ }^{1}$ Menezes N L, Evolution in Velloziaceae, with special reference to androecial characters. Petaloid Monocotyledons: Horticultural and Botanical Research Linnean Society Symposium. Series 1980; 8: 117-139

${ }^{2}$ Menezes, N L; Semir J, Burlemarxia, a new genus of Velloziaceae. Taxon, 1991; 40: 413-426

${ }^{3}$ Smith L M, Ayensu E S. A revision of American Velloziaceae. Smith. Contr. Botanical. 1976; 30: 1-172

${ }^{4}$ Patitucci M L, Veiga Junior V F, Pinto A C, Zoghbi M G, Silva J
R A, Utilização de Cromatografia Gasosa de Alta Resolução na detecção de classe de terpenos em extratos brutos vegetais. Química Nova, 1995; 18: 262-266

${ }^{5}$ Pinto A C, Simoni M S C, Cunha M P C C, Coelho R B, Patitucci M L, Mistura Natural de esteróides, uma alternativa para aplicação de padrões em análises por Cromatografia Gasosa de Alta Resolução. Química Nova; 1994, 17, 333-335 